Editorial

\title{
Promoting bioethics in the Eastern Mediterranean Region
}

Ahmed Mandil ${ }^{7}$ and Phillip Dingwall ${ }^{1}$

Bioethics addresses a broad swathe of human enquiry, ranging from the allocation of scarce health resources to cultural sensitivities over reproductive health. Historically an increasing number of nations have created official bodies to provide advice to their executive and legislative branches, and often to the general public, about bioethics (1). Termed "National Ethics / Bioethics Committees", such bodies are appointed by ministries of health, education, science and technology, or legislatures to synthesize available evidence and offer recommendations about concurrent issues in bioethics, especially as such issues bear on potential needs to develop national policies and to adopt legislations. Health research has grown substantially in the low- and middle-income countries, including the Eastern Mediterranean Region (EMR) (2), with clinical trial activity in some of its nations tripling between 2008 and 2011 (3). However, indigenous scholarship and expertise are essential when examining the complex debates over how health research is conducted and whether effective oversight can be promoted in resource-limited Member States. Moreover, the notion of ethics in any capacity draws in sensitive matters pertaining to cultural and religious values, and applying western concepts of bioethics in their entirety, may not always be an appropriate course to take.

Medical advancements and the emergence of new diseases, as well as the re-emergence of old ones, raise important questions that require ethical considerations. The Ebola outbreak in West Africa and the recent cholera outbreak in Yemen brought up issues of unregulated interventions; the HIV/ AIDS raises issues of equitable access to HIV treatment, testing and counselling; while public health surveillance brings to the fore concerns over informed consent and the provisions of standard of care (4).

A regional survey in 2012 revealed that ethical research guidelines existed in some countries, while research ethics guidance was confined to medical professional guidelines in a few more; the remaining Member States refer to international guidelines (5). In 2015, WHO/EMRO addressed the need to scale up bioethics within the EMR and therefore conducted a bioethics mapping survey in order to identify areas of progress, and where progress is required, in the countries of the Region (6). The survey enabled Member States to prioritize needs and develop appropriate strategies that reflect the specific challenges each Member State faces.

Advances have been made in the EMR to raise training capacity in research ethics, including courses by WHO Regional Office for Eastern Mediterranean (WHO/EMRO) (7), and United Nations Educational, Cultural, Scientific and Cultural Organization (UNESCO) (8). In addition, UNESCO has established centers in a number of educational institutions in the Islamic Republic of Iran, Morocco, Qatar, Saudi Arabia and Tunisia, which now offer postgraduate qualifications in ethics and medical ethics (8).
The WHO 2013 World Health Report placed great emphasis on research for universal health coverage in Member States, including setting the norms and standards for proper research conduct, and expediting the transition of research findings into practical health policy (9). Maintaining standards of scientific rigour and ethical conduct is paramount for research recommended for WHO funding. Therefore, the EMR Research Ethics Review Committee was established in 2007, and reformulated in 2014 to include external (from Egypt, Islamic Republic of Iran, Lebanon, Morocco, Tunisia and UNESCO) and in-house (WHO/EMRO) members. The Committee ensures that its work remains compatible with international standards such as those set down by the Council for International Organizations of Medical Sciences (CIOMS) and UNESCO.

In addition, WHO/EMRO is supporting the establishment of regional WHO collaborating centres on bioethics and ethical conduct of health research, first of which currently considered from Pakistan, i.e. Center for Biomedical Ethics and Culture, Sindh Institute of Urology and Transplantation, to be followed by others considered from the Islamic Republic of Iran and other states. Support for health researchers is highlighted in its Eastern Mediterranean Health Journal through the online publication of the Journal's "Guidelines on the Ethical Conduct and Publication of Health Research" (10). These guidelines provide information on those ethical standards to 
which authors are required to conform in order for submissions can be properly assessed.

At the global level, it is the WHO Global Health Ethics that provides the permanent secretariat for the Global Summit of National Ethics / Bioethics Committees - a biennial forum for national bioethics representatives to share information and experiences on ethical issues in health and public health (1). Ultimately, the Global Summit acts as a platform for discussion and consensus on a wide range of prominent ethical topics. Emphasis on the importance of bioethics in relation to WHO's work in the EMR highlights not only the need to develop national bioethics committees in the EMR, but also how the operations of these bodies should be harmonized in order to maximize their efficacy. In response to the recommendation of the last Global Summit, held in Berlin, 16-18 March, 2016, the first Regional Bioethics Summit for Eastern Mediterranean / Arab States took place 5-6 April 2017 in Muscat, Oman (11) in order to address these very issues, jointly convened by WHO and UNESCO regional offices and headquarters, in collaboration with Sultan Qaboos University and the national bioethics committee of Oman.
By supporting the development of a culture of ethical conduct through effective cooperation and harmonization of procedures and interests between various ethics / bioethics committees throughout the EMR, WHO/EMRO is looking to promote bioethics capacity, training and application in the Region. Ultimately this goal, alongside the work of other UN agencies, academic institutions, and ministries, is to raise awareness of the importance of medical ethics and bioethics as an integral element in regional health and public health promotion and development, for the eventual betterment of our societies as a whole.

\section{References}

1. World Health Organization. Global health ethics. Geneva: World Health Organization; 2016 (http://www.who.int/ethics/partnerships/globalsummit/en/, accessed 8 May 2017).

2. Glickman SW, McHutchison JG, Peterson ED, Cairns CB, Harrington RA, Califf RM, et al. Ethical and scientific implications of the globalization of clinical research. New Engl J Med. 2009; 360(8):816-823.

3. U.S. National Institutes of Health 2011 (http://www.clinicaltrials.gov, accessed 17 May 2017).

4. Alwan A. Ethics and health in WHO regional office for the Eastern Mediterranean. East Mediterr Health J. 2016; 22(1):3 (http://www.emro.who.int/emhj-volume-22-2016/volume22-issue-1/ethics-and-health-in-who-regional-office-for-theeastern-mediterranean.html, accessed 17 May 2017).

5. Alahmad G, Al-Jumah M, Dierick K. Review of national research ethics regulations and guidelines in Middle Eastern Arab countries. BMC Medical Ethics. 2012;13:34

6. Ben Ammar MS, Mandil A, El-Feky S. Ethics in health practice and research: an EMR perspective. East Mediterr Health J. 2016; 22(1):62 (http://www.emro.who.int/emhj-volume-22-2016/ volume-22-issue-1/ethics-in-health-practice-and-research-anemr-perspective.html, accessed 17 May 2017).
7. World Health Organization Regional Office for the Eastern Mediterranean. Research promotion and development. Cairo: WHO Regional Office for the Eastern Mediterranean; 2017 (http://www.emro.who.int/entitiy/research/index.html. accessed 8 May 2017).

8. United Nations Educational Scientific and Cultural Organization (UNESCO). 2013 Ethics education programme. Geneva: UNESCO; 2014 (http://www.unesco.org/new/en/social-andhuman-sciences/themes/bioethics/ethics-education-programme/, accessed 8 May 2017).

9. World Health Organization. World health report: research for universal health coverage. Geneva: World Health Organization; 2013 (http://www.who.int/whr/2013/report/en/, accessed 16 May 2017).

10. EMHJ guidelines on ethical conduct and publication of health research. Cairo: WHO Regional Office for the eastern Mediterranean; 2016 (http://www.emro.who.int/emh-journal/ authors/emhj-guidelines-on-ethical-conduct-and-publication-of-health-research.html, accessed 16 May 2017).

11. World Health Organization Regional Office for Eastern Mediterranean. National ethics and bioethics committees convene in a regional summit. Cairo: WHO Regional Office for the Eastern Mediterranean; 2017 (http://intranet.who.int/features/ emrointranetnews $/$ archive. shtml? year $=\&$ month $=5 \&$ data source=intranet_emro_news\#433739, accessed 8 May 2017). 